\title{
No statistically significant effect of a short-term decrease in the nucleation rate on atmospheric aerosols
}

\author{
E. M. Dunne ${ }^{1,2}$, L. A. Lee ${ }^{1}$, C. L. Reddington ${ }^{1}$, and K. S. Carslaw ${ }^{1}$ \\ ${ }^{1}$ School of Earth and Environment, University of Leeds, Leeds, LS2 9JT, UK \\ ${ }^{2}$ Finnish Meteorological Institute, Kuopio Unit, Kuopio, Finland
}

Correspondence to: E. M. Dunne (eimear.dunne@fmi.fi)

Received: 11 May 2012 - Published in Atmos. Chem. Phys. Discuss.: 18 June 2012

Revised: 23 November 2012 - Accepted: 28 November 2012 - Published: 4 December 2012

\begin{abstract}
Observed correlations between short-term decreases in cosmic ray ionisation and cloud and aerosol properties have been attributed to short-term decreases in the ion-induced nucleation rate. We use a global aerosol microphysics model to determine whether a 10 day reduction of $15 \%$ in the nucleation rate could generate a statistically significant response in aerosol concentrations and optical properties. As an upper limit to the possible effect of changes in ion-induced nucleation rate, we perturb the total nucleation rate, which has been shown to generate particle concentrations and nucleation events in reasonable agreement with global observations. When measured against a known aerosol control state, the model predicts a $0.15 \%$ decrease in global mean cloud condensation nucleus concentration at the surface. However, taking into account the variability in aerosol, no statistically significant response can be detected in concentrations of particles with diameters larger than $10 \mathrm{~nm}$, in cloud condensation nuclei with diameters larger than $70 \mathrm{~nm}$, or in the Ångström exponent. The results suggest that the observed correlation between short-term decreases in cosmic ray ionisation and cloud and aerosol properties cannot be explained by associated changes in the largescale nucleation rate.
\end{abstract}

\section{Introduction}

A link between galactic cosmic rays (GCRs) and the Earth's climate has been observed in multiple data sets over a range of timescales (Svensmark and Friis-Christensen, 1997; Bond et al., 2001; Neff et al., 2001; Kirkby, 2007; Eichler et al.,
2009). However, the cause of this correlation has not yet been identified.

GCRs are made up of highly energetic charged particles which travel through the interstellar medium and impact on the Earth's atmosphere. GCRs create ions pairs when they collide with air molecules, and are the main source of atmospheric ions throughout the free troposphere and an important source in the boundary layer, where radon decay also creates ions (Zhang et al., 2011). The GCR flux is controlled in part by the sun's magnetic activity, leading to variations in flux on timescales of a few days to millennia (Usoskin et al., 2005).

It is not known whether GCRs affect the climate directly through changes in atmospheric composition (such as aerosol and cloud properties) or whether they are a proxy for another climate-influencing factor. Changes in total solar irradiance over the solar cycle $(0.036 \%$ between solar cycles 21 and 22 , Willson, 1997) are much smaller than would be necessary to account for the observed correlations, but changes in the UV portion of the solar spectrum are larger and may affect stratospheric heating, ozone concentrations and the atmospheric general circulation (Haigh, 1996; Haigh et al., 2010). A feedback mechanism which increases subtropical clouds by strengthening the climatological precipitation maxima in the tropical Pacific during northern hemisphere winter has also been proposed by Meehl et al. (2008).

Two mechanisms have been proposed to account for the observed correlations between GCR flux and the climate: the ion-aerosol clear-air effect and the ion-aerosol near-cloud effect (Carslaw et al., 2002). The ion-aerosol near-cloud effect (Tinsley et al., 2000; Harrison, 2008; Harrison et al., 2011) refers to the effects on cloud microphysical properties caused 
by the accumulation of space charge on the top of clouds. Unipolar space charge accumulates due to the electric current flowing into the cloud from the fair-weather electric circuit. It is hypothesised that modulation of the fair-weather current by variations in cosmic ray ionisation could lead to a sequence of micro- and macrophysical responses in clouds. Aerosol particles and cloud droplets in this charged region can accumulate large charges of up to $1500 e$ on individual droplets (Twomey, 1956; Beard et al., 2004), possibly affecting aerosol particle activation (Harrison and Ambaum, 2008), scavenging processes (Wang et al., 1978; Tripathi and Harrison, 2002) and ice nucleation (Tinsley et al., 2000).

In the ion-aerosol clear-air effect, it is hypothesised that changes in the ionisation rate affect the formation of cloud condensation nuclei (CCN), which leads to changes in cloud drop concentrations, cloud albedo and other properties. Several model studies, including Pierce and Adams (2009b), Merikanto et al. (2009) and Yu and Luo (2009), have shown that nucleation in the free troposphere and boundary layer is an important source of global tropospheric CCN, contributing between 23 and $70 \%$ of all $\mathrm{CCN}$ (with the remainder from primary particle emissions). It is hypothesised that if some of these CCN are created through cosmic ray ionisation then global CCN could be influenced by the cosmic ray ionisation rate. The nucleation rate has been shown experimentally to increase with ion concentrations (Kirkby et al., 2011; Enghoff et al., 2011). Pierce and Adams (2009a) found that the effect of changes in cosmic rays over a solar cycle on CCN concentrations would be two orders of magnitude too small to account for observed changes in cloud properties. In a global model study, Yu and Luo (2009) found that ion-mediated nucleation could generate a global aerosol field in good agreement with atmospheric measurements of CCN at $0.4 \%$ supersaturation. Kazil et al. (2012) investigated the sensitivity of the atmosphere to changes in the ion-induced nucleation rate over a solar cycle, but found a negligible response.

Even though nucleation is an important source of $\mathrm{CCN}$, Merikanto et al. (2009) found that a decrease in either the free tropospheric or boundary layer nucleation rate would not result in a proportionate decrease in CCN. A very large fraction of freshly-nucleated particles are lost to the coagulation sink of pre-existing particles, and the proportion of nucleated particles which grow to $\mathrm{CCN}$ sizes is so small, that the response is strongly damped. When the nucleation rate increases, the relative probability of survival decreases as a result of slower growth due to increased competition for condensible vapours and increased self-coagulation of nucleated particles (Pierce and Adams, 2009b). Pierce and Adams (2007) estimated that an average of between 1 and $40 \%$ of nucleated particles go on to form CCN. These studies suggest that large scale changes in nucleation rate would need to be very substantial to have any impact on global CCN and clouds. The enhancement of growth rates of freshly nucleated charged particles compared to corresponding neutral particles is another pos- sible mechanism by which ions could increase the influence of nucleation on the climate, which has not been accounted for in this study.

Attribution of changes in cloud properties to changes in GCR flux over the solar cycle (Svensmark and FriisChristensen, 1997) is hampered because variations in the solar radiation flux may also cause changes in climate variables. To overcome this difficulty, transient decreases in GCR flux on the timescale of a few days have been used instead. During periods of intense solar magnetic activity, streams of coronal matter ejected from the sun can block incoming GCRs. The resulting transient reduction in cosmic ray intensity is known as a Forbush decrease (Forbush, 1946). These short-term decreases in GCR flux, which do not correlate with solar irradiance, have been used to test the GCRclimate connection. The aim of this manuscript is to test the hypothesis that changes in the nucleation rate can account for observed correlations between GCRs and cloud and aerosol properties, and to evaluate the response in aerosol in a way that is transferable to atmospheric observations, taking into account the detectability of the response above global aerosol variability.

One of the earliest studies of the correlation between Forbush decreases and cloud cover was carried out by Pudovkin and Veretenenko (1995). They examined measurements of clear and cloudy skies from observatories in the U.S.S.R. The observatories were divided into three groups based on latitude: $\phi \approx 50^{\circ} \mathrm{N}, \phi \approx 60-64^{\circ} \mathrm{N}$, and $\phi \approx 65-68^{\circ} \mathrm{N}$. They found a decrease in total cloud cover in the two northernmost latitude bands following winter-time Forbush decreases. In the latitudinal belt $\phi \approx 60-64^{\circ} \mathrm{N}$, on the days immediately following winter-time Forbush decreases, the sky was more likely to be clear and less likely to be cloudy at noon.

Svensmark et al. (2009) observed a correlation between a selection of five Forbush decreases and four separate data sets of cloud and aerosol properties. They examined the Ångström exponent at $340-440 \mathrm{~nm}\left(\mathrm{AE}_{340-440}\right)$ as measured by AERONET, the cloud water content measured by the Special Sensor Microwave/Imager (SSM/I), liquid water cloud fraction measured by the Moderate Resolution Imaging Spectroradiometer (MODIS), and low IR-detected clouds compiled by the International Satellite Cloud Climatology Project (ISCCP). These data sets were compared with neutron counts from CLIMAX, Colorado. They found minima in each of the data sets after lags of between 4 and 10 days from the minimum of the Forbush decrease and concluded that the minima were likely to be due to short-term changes in the ion-induced nucleation rate.

The findings of Svensmark et al. (2009) have been questioned and the relevant data sets re-examined in several papers. Laken et al. (2009) examined the MODIS liquid water cloud fraction data for evidence of a decrease following Forbush decreases. They found that the short-term decreases presented in Svensmark et al. (2009) are not anomalous when viewed as part of a longer-term time series, and 
that the apparent response to Forbush decreases in Svensmark et al. (2009) was dominated by a single event on 19 January 2005. They found no evidence that the decrease in liquid water cloud fraction on 19 January 2005 or in the mean of the five events studied by Svensmark et al. (2009) was causally linked to Forbush decreases. Laken et al. (2009) concluded that the observed time delay in the liquid water cloud fraction response was longer than expected if it were due to changes in the ion-induced nucleation rate, although Svensmark et al. (2009) cite two models which suggest growth rates on the order of days (Russell et al., 1994; Arnold, 2007).

In Laken et al. (2010), a statistical analysis of short-term decreases in cloud cover showed a correlation with decreases in GCR flux. Rather than examine cloud properties during periods of unusual activity in GCR flux, they found periods during which satellite observations of visible and infrared clouds underwent abrupt change. Laken et al. (2010) found that when mid-latitude clouds experienced a relative decrease over a short time scale, GCR flux also underwent a statistically significant decrease. They concluded that shortterm changes in the cosmic ray flux are likely to affect cloud properties under suitable atmospheric conditions, but it was unlikely to be via a first-order effect.

C̆alogović et al. (2010) performed a statistical comparison of infrared ISCCP cloud cover data (Rossow, 1996) with changes in the atmospheric ionisation rate caused by Forbush decreases. By using $5^{\circ} \times 5^{\circ}$ grid boxes with a temporal resolution of three hours, they were able to improve their statistical analysis compared with previous cosmic ray-cloud comparisons, which looked at monthly global means (e.g. Marsh and Svensmark, 2000). They tested for correlations at three different altitude levels across a range of time lags from 0 to 10 days. They concluded that the small correlation found in the cloud data was not caused by changes in the GCR flux. Laken and Čalogović (2011) also conclude that none of the solar effects examined in the paper (changes in total solar irradiance, GCR flux, and $10.7 \mathrm{~cm}$ solar radio flux) corresponds to a statistically significant change in cloud cover.

In the most recent study, Svensmark et al. (2012) examined MODIS data for six variables for the same five Forbush decreases used in Svensmark et al. (2009). They again concluded that they had observed a response to Forbush decreases in the MODIS data at various significance levels but independent analyses reached the opposite conclusion (Rypdal, 2012; Laken and C̆alogović, 2012; Dunne, 2012).

Bondo et al. (2010) used a box model to test the response of marine aerosol optical properties to a change in the ionisation rate. They modelled secondary aerosol formation in the presence of a population of primary sea-salt aerosol, and its subsequent growth via condensation of sulphuric acid and coagulation. They then calculated the aerosol optical depth from the modelled size distribution. The microphysical processes employed by Bondo et al. (2010) were relatively simplistic. Their nucleation rate was assumed to be constant aside from a linear dependence on ion concentrations $I$. Nu- cleation is a complex process with strong dependencies on, for example, temperature and sulphuric acid concentration. Bondo et al. (2010) do not include a diurnal cycle in their sulphuric acid production rate.

Bondo et al. (2010) suggested that the decrease in Ångström exponent observed by Svensmark et al. (2009) was caused by an increase in aerosol effective radius due to a reduction in nucleation. They were able to tune the parameters used in their model to produce a decrease in the Ångström exponent. However, their simulations had unusually high production rates of sulphuric acid and low nucleation rate - conditions which would cause the greatest sensitivity to the nucleation rate, but are not consistent with atmospheric observations. The modelled sulphuric acid production rate of $P_{\mathrm{H}_{2} \mathrm{SO}_{4}}=20000 \mathrm{~cm}^{-3} \mathrm{~s}^{-1}$ led to a sulphuric acid concentration of $5 \times 10^{7} \mathrm{~cm}^{-3}$, which is higher than expected in a marine environment. For example, Berresheim et al. (2002) found daily mean $\mathrm{H}_{2} \mathrm{SO}_{4}$ concentrations of $2.6 \times 10^{6} \mathrm{~cm}^{-3}$ in coastal air in June 1999, with a mean daily maximum of $1.04 \times 10^{7} \mathrm{~cm}^{-3}$. Concentrations are likely to be much lower over remote ocean regions. At these concentrations, the activation nucleation mechanism of Kulmala et al. (2006) would predict a nucleation rate of $J_{\text {act, } 1.5}=2 \times 10^{-6} \times 5 \times 10^{7}=$ $100 \mathrm{~cm}^{-3} \mathrm{~s}^{-1}$ (assuming a rate coefficient $A=2 \times 10^{-6} \mathrm{~s}^{-1}$, (Sihto et al., 2006)), much higher than the constant background rate of $0.001 \mathrm{~cm}^{-3} \mathrm{~s}^{-1}$ assumed by Bondo et al. (2010). Thus Bondo et al. (2010)'s idealised simulations appear to be outside the atmospheric range.

Snow-Kropla et al. (2011) used a global aerosol microphysics model to test the response of the number concentration of particles with diameter greater than $10 \mathrm{~nm}\left(\mathrm{~N}_{10}\right)$ and $80 \mathrm{~nm}\left(\mathrm{CCN}_{80}\right)$ and Ångström exponent to a simulated Forbush decrease. They used the ion-mediated nucleation lookup tables of Yu (2010), and calculated the ionisation rate using the method of Usoskin and Kovaltsov (2006). SnowKropla et al. (2011) simulated eight Forbush decrease events by changing the sun's modulation of cosmic rays from a value equivalent to solar maximum to a value equivalent to solar minimum, followed by five days of linear recovery to the solar maximum value. The simulated nucleation rate at solar minimum was 1 to $5 \%$ higher than during solar maximum. Their methods were more sophisticated than Bondo et al. (2010), as their model accounts for several factors neglected by Bondo et al. (2010) which could dampen the sensitivity of the aerosol system to a change in nucleation, including the coagulation of secondary aerosol with primary particles, and an explicit simulation of free tropospheric nucleation. They found that the concentration of particles larger than $10 \mathrm{~nm}$ changed by $0.16 \%$ and $\mathrm{CCN}$ with diameter greater than $80 \mathrm{~nm}$ changed by $0.13 \%$ in the days following the Forbush decrease, with a delay of a week before the minimum in $\mathrm{CCN}_{80}$. The delay is consistent with growth rates observed by Kulmala et al. (2004). However, they concluded that these changes would not be sufficiently large to alter cloud properties. The response in Ångström exponent 
was 100 times smaller than that observed in Svensmark et al. (2009). While Snow-Kropla et al. (2011) did test for significance, their figures only show a confidence interval about the percentage response, and not the significance level of the absolute change.

\section{Method}

We want to test the hypothesis that changes in the nucleation rate can account for observed correlations between GCRs and cloud and aerosol properties. We also aim to evaluate the response in aerosol in a way that is transferable to atmospheric observations, taking into account the detectability of the response above global aerosol variability. We do this by quantifying the response of several aerosol parameters to a change in the nucleation rate, using the global aerosol microphysics model GLOMAP.

\subsection{Description of the aerosol model}

The global aerosol microphysics model GLOMAP is an extension of the TOMCAT 3-D global chemical transport model (Chipperfield, 2006) driven by European Centre for Medium-Range Weather Forecasts (ECMWF) re-analyses. GLOMAP uses a $2.8^{\circ} \times 2.8^{\circ}$ horizontal grid and has 31 vertical pressure levels. This study uses GLOMAP-bin, a twomoment sectional model that simulates both particle number concentrations and component masses of sulphate, particulate organic matter (from primary and secondary sources), sea salt, and black carbon (Spracklen et al., 2005; Merikanto et al., 2009). GLOMAP simulates nucleation, condensation of sulphuric acid and organic vapours onto pre-existing aerosol, coagulation, dry deposition and nucleation scavenging. GLOMAP has been evaluated against a wide range of global aerosol microphysical observations, including surface and free tropospheric measurements of particle concentrations (Spracklen et al., 2007, 2010; Reddington et al., 2011) and nucleation events (Spracklen et al., 2006). The model uses the AEROCOM emissions inventory for $\mathrm{SO}_{2}$, black carbon and organic carbon. Primary carbonaceous (BC/OC) particles are emitted assuming the log-normal size distribution suggested by Dentener et al. (2006) (fossil fuel emissions: $D=30 \mathrm{~nm}, \sigma=1.8$; wildfire and biofuel emissions: $D=80 \mathrm{~nm}, \sigma=1.8$ ). Primary (sub-grid) $\mathrm{SO}_{4}$ particles are emitted as $2.5 \%$ of $\mathrm{SO}_{2}$ emissions also assuming the lognormal size distribution recommended by Dentener et al. (2006) (road transport: $D=30 \mathrm{~nm}, \sigma=1.8$; shipping, industry and power-plant emissions: $D=1 \mu \mathrm{m}, \sigma=2.0$; wildfire and biofuel emissions: $D=80 \mathrm{~nm}, \sigma=1.8$; volcanic emissions: $50 \%$ at $D=30 \mathrm{~nm}$ and $50 \%$ at $D=80 \mathrm{~nm}, \sigma=1.8$ ). The DMS emissions are driven by sea-air tranfer velocity parametrisation of Nightingale et al. (2000). Sea salt was emitted using the flux parametrisation of Smith and Harrison (1998) and Gong (2003).
Good agreement has been shown between GLOMAP and aerosol observations when using a combination of the binary homogeneous nucleation mechanism of Vehkamäki et al. (2002) in the free troposphere with a boundary layer nucleation, as described in Spracklen et al. (2006). We use the activation-based empirical boundary layer nucleation mechanism of Sihto et al. (2006) to model new particle formation rates at $1.5 \mathrm{~nm} J_{\text {act, } 1.5}=2 \times 10^{-6} \mathrm{~s}^{-1}\left[\mathrm{H}_{2} \mathrm{SO}_{4}\right]$. The particles are then grown to $3 \mathrm{~nm}$ using the formula of Kerminen and Kulmala (2002). Typical monthly mean modelled surface nucleation rates for July are $\sim 10^{-5}-10^{-2} \mathrm{~cm}^{-3} \mathrm{~s}^{-1}$ over the ocean, and $10^{-3}-10^{0} \mathrm{~cm}^{-3} \mathrm{~s}^{-1}$ over land. The mechanism of Sihto et al. (2006) depends only on sulphuric acid concentration and does not account for temperature or concentrations of other precursor vapours. Yu et al. (2010) and Zhang et al. (2010) show that this mechanism may significantly overpredict nucleation rates under some conditions. However, evaluation against ambient measurements shows that it is one of the best predictors of particle concentrations in the boundary layer (Spracklen et al., 2006, 2010).

Previous nucleation studies in GLOMAP have used the neutral binary homogeneous nucleation parametrisation of Kulmala et al. (1998), but this study uses the improved parametrisation of Vehkamäki et al. (2002). The latter is more physically accurate, as it takes the formation of sulphuric acid hydrates into account and predicts the critical cluster size. The effective change in the modelled nucleation rate is quite small, due to losses of sub- $3 \mathrm{~nm}$ particles, so the model validation carried out with the parametrisation of Kulmala et al. (1998) remains valid (J. Merikanto, personal communication, 2011). No ion-induced nucleation parametrisation has been implemented in GLOMAP at this time, hence the use of of a neutral nucleation mechanism in this study. The sensitivity of the aerosol system could change with the assumed nucleation rate, but the nucleation schemes chosen in this paper are consistent with observed $N_{10}$ concentrations (Spracklen et al., 2010).

\subsection{Design of the experiments}

Our approach is to assume that the global 3-D nucleation rates in GLOMAP are approximately correct (based on agreement with observations) and to perturb these rates to test an upper limit of the effect of Forbush decreases on CCN. The scaling of the nucleation rate in the unperturbed and perturbed runs is shown in Fig. 1.

The relative proportion of nucleated particles derived from charged and neutral processes is very uncertain. Analysis of observations suggests that the contribution of ion-induced nucleation to new particle formation events is between $6 \%$ and $15 \%$ in the continental boundary layer (Laakso et al., 2007; Boy et al., 2008; Gagné et al., 2008; Manninen et al., 2009), while one model suggests that as much as $80 \%$ of nucleation events could be ion-mediated (Yu and Turco, 2008, 2011). Boundary layer nucleation is likely to have a lower 


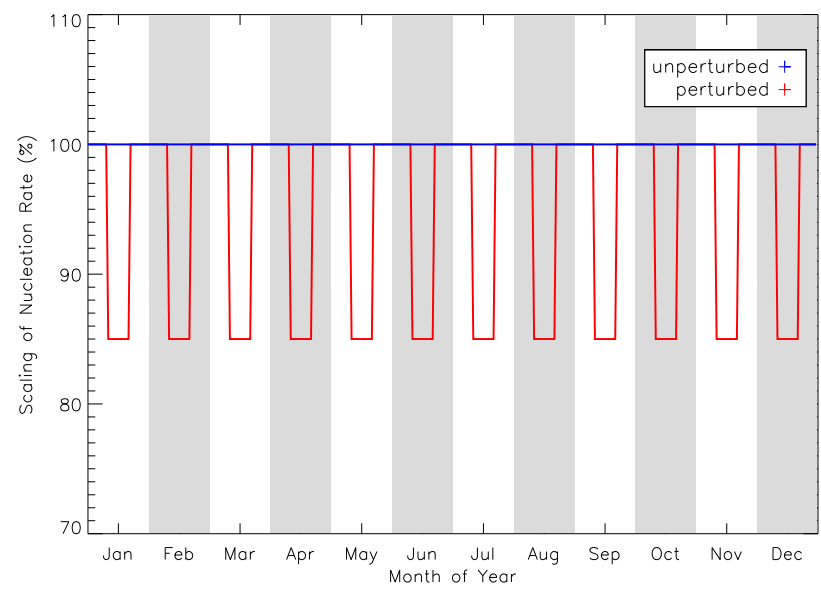

Fig. 1. Schematic of how the nucleation rate is scaled throughout the year. In the perturbed simulations (red), the nucleation rate was scaled to $85 \%$ of its calculated value for the middle ten days of each month.

ion-induced fraction than free tropospheric nucleation, due to the expected dependence of high-temperature nucleation on ternary vapours which will reduce the need for stabilising ions (Kirkby et al., 2011).

In this paper, we assume that all nucleation is reduced by $15 \%$ for 10 days during a Forbush decrease. This implicitly assumes that $100 \%$ of nucleation is ion-induced, and that ion concentrations will decrease by $15 \%$ during a Forbush decrease when the ionisation rate decreases by $15 \%$. Both of these implicit assumptions are known to be inaccurate (Kirkby et al., 2011; Usoskin and Kovaltsov, 2006). Neutral nucleation also occurs and is likely to dominate in some parts of the atmosphere. Ion concentrations do not depend linearly on ionisation rates, and indeed the ionisation rate does not change by a uniform percentage throughout the atmosphere during a Forbush decrease. Depending on the relative proportions of neutral and ion-induced nucleation, the actual decrease in the nucleation rate resulting from a Forbush decrease could be much smaller than we simulate here.

The model was spun up for three months and then run for one year in control and perturbed simulations. The control simulation used the binary homogeneous nucleation parametrisation of Vehkamäki et al. (2002) in the free troposphere and an activation-based boundary layer mechanism (Sihto et al., 2006; Spracklen et al., 2006). In the perturbed simulation, the calculated nucleation rate was scaled by 0.85 throughout the atmosphere for 10 days in the middle of each 30-day period. This decrease corresponds to the largest magnitude of the Forbush decreases used by Svensmark et al. (2009) and Bondo et al. (2010). The first 10 days of each month are identical in the unperturbed and perturbed simulations. Since we do not know a priori the magnitude or timescale of the aerosol response, we analyse the full thirtyday periods rather than the ten days of reduced nucleation.
The 12 sets of 30-day periods were analysed using equal epoch analysis techniques (Forbush et al., 1983). This technique has been used in the past to amplify the signal to noise ratio when analysing responses in atmospheric ion concentrations to Forbush decreases. We assume that any response to the perturbation will occur approximately at the same time in each 30-day period. By simulating twelve different months over a full year, rather than the same month from different years, we can determine whether there is a stronger response to a short-term change in the nucleation rate at any point during the seasonal cycle. By comparing otherwise identical sets of unperturbed and perturbed simulations, we can attribute any observed change directly to the simulated short-term decrease in the nucleation rate.

We analyse three model diagnostics: the global mean concentration of aerosol particles with dry diameters greater than $10 \mathrm{~nm}\left(N_{10}\right)$ and $70 \mathrm{~nm}\left(\mathrm{CCN}_{70}\right)$ and the Ångström exponent $\mathrm{AE}_{340-440}$. Aerosol optical depth (AOD) is a measure of the extinction of light of a given wavelength by aerosol scattering and absorption. When AOD has been measured for two wavelengths $\lambda_{1}$ and $\lambda_{2}$, the Ångström exponent (AE) can be calculated as follows:

$\mathrm{AE}=\frac{-\log \frac{\mathrm{AOD}_{\lambda_{1}}}{\mathrm{AOD} \lambda_{2}}}{\log \frac{\lambda_{1}}{\lambda_{2}}}$.

The Ångström exponent provides indirect information on the aerosol size distribution; for example, in a bimodal distribution $\mathrm{AE}_{340-440}$ responds to the fine mode aerosol radius, while the Ångström exponent calculated from longer wavelength pairs would provide information on the fine mode fraction of aerosols (Schuster et al., 2006).

\subsection{Statistical analysis}

The purpose of the statistical tests is to determine whether some additional forcing (here a change in the nucleation rate) has increased the variability of the data beyond what would be expected from the natural fluctuations of the system. When testing for statistical significance, we first need to define a null hypothesis $H_{0}$ and then perform a test to accept or reject that null hypothesis. $H_{0}$ here is that several samples are from the same underlying population. The samples in this case are the 30 days of the 12 periods defined by the equal epoch analysis. The test of this hypothesis will be the analysis of variance (ANOVA). The aim is to identify any day in which the perturbed nucleation rate has altered the properties of the day away from the underlying population by comparing the variance within each sample to the variance across all samples. In order to remove the effect of external factors such as meteorology, we first remove the trend in each month - this is common practice in tests regarding the variance of the errors where the trend is not of interest. We also check the validity of the statistical tests before performing them. 
The statistical tests used here rely on the assumptions that the errors (deviations from the mean) are independent and follow a normal distribution with homogeneous variances. The tests are robust to slight deviations from these assumptions, but may be invalid with large deviation (Forbush et al., 1982), so we test the errors for both normality and homogeneity of variances. The data are known to contain autocorrelations and therefore the assumption of independence is violated. If necessary, the tests can be corrected in the presence of autocorrelations as discussed in Sect. 2.3.5.

\subsubsection{Removal of trend}

Over the course of a year, concentrations of atmospheric aerosol change substantially. These changes make it difficult to extract the signal of interest. We process our data to remove linear trends from each month without changing the properties of the deviations from this trend that are the focus of our analysis. None of the papers cited in Sect. 1 investigating the Forbush decrease-cloud link removed trends from the data, meaning that the spread between epochs would smear an underlying normal distribution.

The 360 data points $\left(Y_{i j}\right)$ are divided into $I=12$ samples of $J=30$ observations. We fit a line to each of the $i=1, \ldots$, 12 months' data, with slope $m_{i}$ and intercept $c_{i}$, where the abscissa values $j$ are the days of the month:

$Y_{i j, \mathrm{fit}}=m_{i} j+c_{i}$.

A new data set is defined as

$X_{i j}=Y_{i j}-m_{i} j-c_{i}$

\subsubsection{Testing for normality}

If the true distribution is different from a normal distribution, the results of these tests may not be valid. For example, if the distribution has fat tails, fluctuations that are within the true $95 \%$ confidence interval can be found to be statistically significant using tests designed for normal distributions. It is widely assumed that data are normal, although it is less common to use statistical tests to confirm normality. It is important to choose an appropriate test for the data; if there are strong autocorrelations the null hypothesis of normality can be incorrectly rejected.

To determine whether our Ångström exponent and concentrations of $\mathrm{N}_{10}$ and $\mathrm{CCN}_{70}$ are normally distributed, the Lilliefors test was applied (Lilliefors, 1967). The Lilliefors test is a modified Kolmogorov-Smirnov test (Massey, 1951), which does not require that the normal distribution to which the sample belongs be specified. The Kolmogorov-Smirnov test is a more robust test of normality than the ShapiroWilk test when dealing with the autocorrelations present in time series (Shapiro and Wilk, 1965; Durilleul and Legendre, 1992). The null hypothesis used in this test is that the data are normally distributed.

\subsubsection{Testing for homogeneous variances}

Forbush et al. (1983) highlight the problems associated with carrying out an analysis of atmospheric data. They give a detailed step-by-step process for carrying out an equal epoch analysis correctly. One step is the testing of variances between days to confirm their homogeneity - that is, that each day has approximately the same variance between months. We use the Brown-Forsythe test for homogeneity of variances (Brown and Forsythe, 1974). We define a new data set $Z_{i j}=\left|X_{i j}-\bar{X}_{\cdot j}\right|$ and compare the test statistic $W$ against $F_{\alpha}$ for $(J-1, I J-J)$ degrees of freedom, where

$$
\begin{aligned}
W= & {\left[(I J-J) \sum_{j=1}^{J=30} I\left(Z \cdot j-Z_{. .}\right)^{2}\right] / } \\
& {\left[(J-1) \sum_{j=1}^{J=30} \sum_{i=1}^{I=12}\left(Z_{i j}-Z_{. j}\right)^{2}\right] . }
\end{aligned}
$$

\subsubsection{Plotting the data}

A useful step in any statistical analysis is to visualise the data. When the normality assumption has been verified we can draw meaningful confidence intervals around the data for each day and plot it. This will help us to understand the results of any statistical tests and their conclusions. To give a sense of scale, we have added the ensemble mean of the unprocessed data $\bar{Y}=\sum_{i=1}^{I} \sum_{j=1}^{J} Y_{i j} / I J$ back to each data point $X_{i j}$ when plotting graphs. This has no effect on the statistical analysis.

For a normally distributed population, with mean $\mu$ and standard deviation $\sigma, 95 \%$ of the distribution lies within two standard deviations of the mean, in the range $[\mu-2 \sigma$, $\mu+2 \sigma]$. When we have only a sample from the population, however, we should instead use Student's t-statistic to calculate the $95 \%$ confidence interval from the sample mean $\bar{X}$ and the sample standard deviation $S$. The interval $\left[\bar{X}-t_{\alpha / 2, N-1} S, \bar{X}+t_{\alpha / 2, N-1} S\right]$ is estimated to contain $(1-\alpha)$ of the population from which the sample has been drawn, where $\alpha$ is the confidence level (usually 0.05 ), $N$ is the sample size, and $t_{\alpha / 2, N-1}$ is Student's t-statistic for confidence level $\alpha$ and $(N-1)$ degrees of freedom.

We form a time series of 30 daily means $\bar{X}_{. j}$ for each day of the 12 combined months, and for each of these means we have a sample variance calculated for that day from the $I=$ 12 months:

$S_{j}=\sqrt{\frac{\sum_{i=1}^{I=12}\left(X_{i j}-\bar{X}_{\cdot j}\right)^{2}}{I-1} .}$

The $95 \%$ confidence interval of each day's distribution is then

$\bar{X}_{\cdot j} \pm t_{\alpha / 2, I-1} S_{j}$ 
The $95 \%$ confidence interval for the true mean $\mu$ of a population from a sample is

$\mu=\bar{X} \pm t_{\alpha / 2, N-1} S / \sqrt{N}$.

The size of the confidence interval about the mean is reduced by increasing the sample size.

\subsubsection{Dealing with autocorrelation in the data}

Atmospheric data generally contain autocorrelations, resulting in their not being sequentially independent. Forbush et al. (1982) do not discuss autocorrelation, but instead focus on the similar phenomenon of quasi-persistency. Quasipersistency occurs when a data set includes a periodic signal, and sequential epochs of approximately the length of the period are analysed. The periodicity will lead to correlation between epochs. Both autocorrelated and quasi-persistent data have a smaller variance about their mean than would be the case for independent data.

When dealing with autocorrelated data, the number of independent data points (effective sample size) is calculated and used to scale the sample variance (Wilks, 1997). This results in a larger confidence interval than when autocorrelations are neglected, making it less likely that a response will be deemed statistically significant. For data with quasipersistency, the number of independent epochs (effective length of sequences) is equivalent, and should be accounted for when testing for significance (Forbush et al., 1983). Because aerosol properties are not periodic on monthly timescales, we do not need to account for quasi-persistency in our data.

\subsubsection{Analysis of variance (ANOVA)}

To determine whether any of the days is statistically significantly different from the others we use analysis of variance (ANOVA), otherwise known as the F-test. If our modelled change in the nucleation rate causes a statistically significant response on any day of the month, the F-test will detect it. Our experimental design is equivalent to a randomised block design examining $I \times J$ observations divided into $I$ blocks of $J$ observations.

The signal variance between days is

$S_{\mathrm{c}}^{2}=I \sum_{j=1}^{J=30}\left(\bar{X}_{\cdot j}-\bar{X}_{. .}\right)^{2} /(J-1)$.

The signal variance between months or epochs is

$S_{\mathrm{r}}^{2}=J \sum_{i=1}^{I}\left(X_{i .}-\bar{X}_{. .}\right)^{2} /(I-1)$.

We expect $S_{\mathrm{r}}^{2}$ to be small due to the processing described in Sect. 2.3.1. The total variance is

$S_{\mathrm{T}}^{2}=\sum_{i=1}^{I} \sum_{j=1}^{J}\left(X_{i j}-\bar{X}_{. .}\right)^{2} /(I J-1)$ and the residual variance is

$S_{\mathrm{R}}^{2}=\frac{(I J-1) S_{\mathrm{T}}^{2}-(J-1) S_{\mathrm{c}}^{2}-(I-1) S_{\mathrm{r}}^{2}}{(I-1)(J-1)}$.

The method of Forbush et al. (1983) uses an estimate of the variance between measurements on different days $\left(S_{\mathrm{c}}^{2}\right)$, and an estimate of the residual variance of all measurements $\left(S_{\mathrm{R}}^{2}\right)$. The ratio of these estimates, $F$, is then compared with a critical value $F_{\alpha}$, which depends on the degrees of freedom of the two estimates of variance. If $F=S_{\mathrm{c}}^{2} / S_{\mathrm{R}}^{2}>F_{\alpha}$, the null hypothesis that the variance between days is smaller than the residual variance is rejected.

We are considering 30 samples of 12 measurements. This means that the numerator has $J-1=29$ degrees of freedom, and the denominator has $(J-1)(I-1)=319$ degrees of freedom. This gives a value of $F_{\alpha}=1.5032$ for a confidence level of $\alpha=0.05$. If we were attempting to show that $S_{\mathrm{c}}^{2}=S_{\mathrm{R}}^{2}$, then if $F<1$ we would test $1 / F$ against $F_{\alpha}(\alpha / 2,(J-1)(I-1),(J-1))$ (Hald, 1952). However, we are satisfied with demonstrating that the variance between days $S_{\mathrm{c}}^{2}$ is less than or equal to the residual variance of the system $S_{\mathrm{R}}^{2}$.

Because the days were not assigned randomly to blocks, but are part of a defined sequence, autocorrelations between days would be expected to increase the value of $S_{\mathrm{c}}^{2}$. However, when we took autocorrelations into account, we found that the value of $S_{\mathrm{R}}^{2}$ also increased, and as a result $F$ was found to decrease. The changes in degrees of freedom would also have resulted in an increase in $F_{\alpha}$. Our conclusions would have remained unchanged, so we chose to neglect autocorrelations during our analysis.

We will carry out the same analysis on each of the outputs listed in Sect. 2.1 for both the perturbed and unperturbed data. The outputs will be tested as a global mean and also at the grid box level so that regional effects of the Forbush decrease can be identified. Furthermore, the perturbed and unperturbed data sets will be compared to identify any effect of the change in the nucleation rate even when this is shown not to be significant.

\section{Results and discussions}

Changes in aerosol concentrations were examined at three different altitude levels: the surface model level, $1-3 \mathrm{~km}$ and $10-15 \mathrm{~km}$ a.s.l. The surface model layer is of interest because it is where most real-world observations are made. Altitudes of $1-3 \mathrm{~km}$ include low clouds that are sensitive to changes in $\mathrm{CCN}$. Both the highest ionisation rates due to cosmic rays and the largest response to a change in incoming GCR flux occur at altitudes of about 10-15 km. Nucleation is also the dominant source of aerosol at this altitude, so one would expect that any response in aerosol properties would 

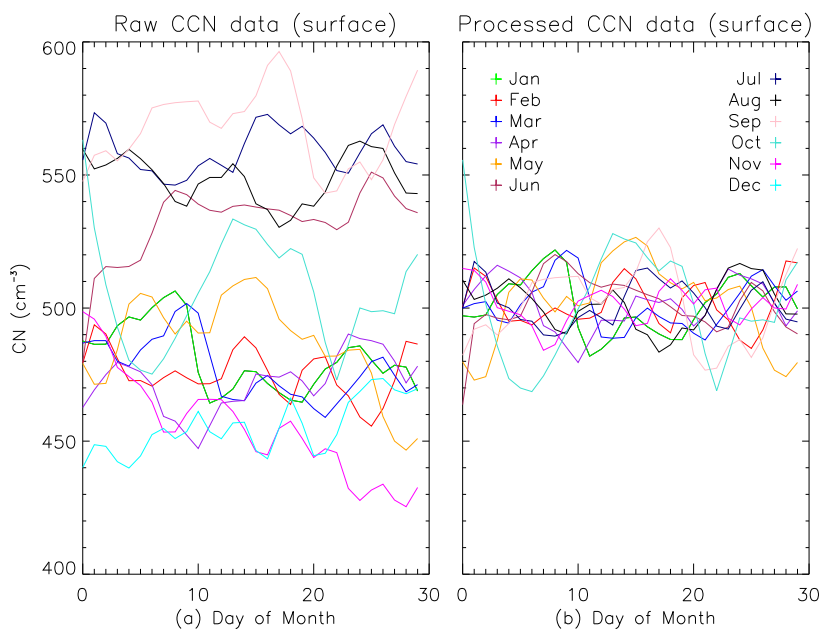

Fig. 2. Time series of unprocessed (left panel) and processed (right panel) surface $\mathrm{CCN}_{70}$ concentrations. The removal of the trend makes it possible to analyse the 12 samples together, but the intrasample variance remains unchanged. The ensemble mean has been added back to each data set for graphical purposes.

be particularly noticeable. Ångström exponent is a columnintegrated quantity.

We describe the analysis of surface $\mathrm{CCN}_{70}$ in detail, followed by a summary of the findings for the other quantities.

\subsection{Global mean surface $\mathrm{CCN}_{70}$}

\subsubsection{Testing for normality}

Surface $\mathrm{CCN}_{70}$ were subjected to the Lilliefors test after de-trending (Sect. 2.3.1). The de-trended surface $\mathrm{CCN}_{70}$ for each month are shown as a time series in Fig. 2. Removing the trend in each month allows us to analyse all 360 data points as a single sample. The probability distributions for de-trended and raw surface $\mathrm{CCN}_{70}$ in Fig. 3 show that the raw data has a much wider spread with two small peaks. The difference between the raw and de-trended distributions shows the importance of correctly processing the data before carrying out statistical tests.

The results of the Lilliefors and Brown-Forsythe tests on de-trended data are shown in Table 1. $P$ is the probability of obtaining a test statistic of equal or greater value than observed, in the case where the null hypothesis is true. A larger p-value means that data are more likely to be normally distributed. If the test statistic KSTAT is larger than the tabulated critical value for a given sample size, the null hypothesis that the data are normally distributed is rejected. Table 1 shows that the null hypothesis of normality was not rejected for surface $\mathrm{CCN}_{70}$. The Brown-Forsythe test found that the variances on different days of the month were slightly inhomogeneous, but according to Forbush et al. (1982), moderate
Table 1. Statistics returned by the Lilliefors test and the BrownForsythe test on Ångström exponent and on $N_{10}$ and $\mathrm{CCN}_{70}$ at the surface, $1-3 \mathrm{~km}$, and $10-15 \mathrm{~km}$. If the test statistic KSTAT is larger than 0.05 , the null hypothesis that the data are normally distributed is rejected. The null hypothesis is rejected for $\mathrm{CCN}_{70}$ and $\mathrm{AE}_{340-440 \mathrm{~nm} .} W$ and $W^{\prime}$ are the Brown-Forsythe test statistics for unperturbed and perturbed data respectively. If $W$ or $W^{\prime}>F_{\alpha}=$ 1.502, the variances are not homogeneous; however, Forbush et al. (1982) say that moderate departures from homogeneous variances will not have a large effect on the results of the tests.

\begin{tabular}{lrrrrr}
\hline & $H$ & $P$ & KSTAT & $W$ & $W^{\prime}$ \\
\hline Surface $N_{10}$ & 0 & 0.483 & 0.032 & 1.80 & 1.73 \\
$N_{10}$ at $1-3 \mathrm{~km}$ & 0 & 0.191 & 0.040 & 1.29 & 1.39 \\
$N_{10}$ at $10-15 \mathrm{~km}$ & 0 & 0.053 & 0.047 & 2.02 & 2.08 \\
Surface $\mathrm{CCN}_{70}$ & 0 & $>0.5$ & 0.028 & 1.21 & 1.14 \\
$\mathrm{CCN}_{70}$ at $1-3 \mathrm{~km}$ & 0 & 0.153 & 0.041 & 1.51 & 1.42 \\
$\mathrm{CCN}_{70}$ at $10-15 \mathrm{~km}$ & 1 & 0.003 & 0.061 & 3.12 & 3.12 \\
$\mathrm{AE}_{340-440}$ & 1 & 0.004 & 0.059 & 1.55 & 1.59 \\
\hline
\end{tabular}

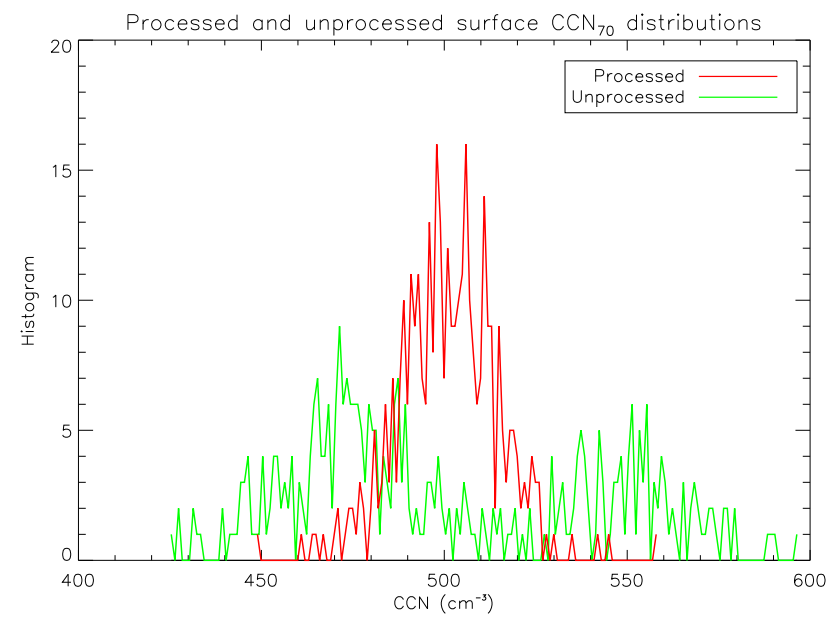

Fig. 3. Histograms showing the distribution of processed and unprocessed surface $\mathrm{CCN}_{70}$ concentrations. The null hypothesis that the red line (processed) is normally distributed is not rejected by the Lilliefors test.

departures from homogeneous variances will not have a large effect on the results of the tests.

\subsubsection{Testing for significance}

The F-test was used to determine whether the aerosol properties exhibited a statistically significant difference on any day of the month. We initially tested the model control (unperturbed) run, to confirm that any observed significance in the perturbed data was due solely to the decrease in the nucleation rate. The results of the F-tests on unperturbed and perturbed data are shown in Table 2. 
Table 2. Results of F-tests on $N_{10}, \mathrm{CCN}_{70}$ and Ångström exponent. $\mathrm{CCN}_{70}$ at 10-15 km and Ångström exponent are included for reference, but were found not to be normally distributed. $F_{\alpha}=1.5020$. Symbols with primes refer to perturbed data.

\begin{tabular}{lrrrrrrrr}
\hline & $S_{\mathrm{c}}^{2}$ & $S_{\mathrm{R}}^{2}$ & $F$ & $>F_{\alpha}$ & $S_{\mathrm{c}}^{\prime 2}$ & $S_{\mathrm{R}}^{\prime 2}$ & $F^{\prime}$ & $>F_{\alpha}^{\prime}$ \\
\hline Surface $N_{10}$ & 395.7 & 423.6 & 0.93 & No & 491.2 & 413.19 & 1.19 & No \\
$N_{10}(1-3 \mathrm{~km})$ & 251.4 & 574.8 & 0.44 & No & 503.1 & 560.9 & 0.90 & No \\
$N_{10}(10-15 \mathrm{~km})$ & 466.1 & 2302.1 & 0.18 & No & 533.2 & 2298.6 & 0.21 & No \\
${\text { Surface } C C N_{70}}_{\mathrm{CCN}_{70}(1-3 \mathrm{~km})}$ & 84.4 & 141.7 & 0.60 & No & 85.7 & 142.3 & 0.60 & No \\
$\mathrm{CCN}_{70}(10-15 \mathrm{~km})$ & 1.48 & 106.0 & 0.52 & No & 54.1 & 106.4 & 0.51 & No \\
$\mathrm{AE}_{340-440 \mathrm{~nm}}$ & 0.00048 & 0.00060 & 0.46 & No & 1.84 & 3.19 & 0.58 & No \\
\hline
\end{tabular}

We calculated the variance between different days $S_{\mathrm{c}}^{2}$ (Eq. 8) and the residual variance of the data $S_{\mathrm{R}}^{2}$ (Eq. 11).

$S_{\mathrm{c}}^{2}=84.4401$

$S_{\mathrm{R}}^{2}=141.724$

Their ratio is $F=0.596<F_{\alpha}=1.5032$. Thus the null hypothesis that all days are drawn from the same overall population was not rejected. The same calculations were then carried out using the perturbed data.

$S_{\mathrm{c}}^{2}=85.7378$

$S_{\mathrm{R}}^{2}=142.263$

$F=\frac{85.7378}{142.263}=0.603<F_{\alpha}=1.5032$

The null hypothesis that all days are drawn from the same overall population was not rejected.

Figure 4a shows the time series of daily mean surface $\mathrm{CCN}_{70}$, with the error bars showing the $95 \%$ confidence interval of the daily distributions (Eq. 6). The solid horizontal line shows the ensemble mean, and the dashed horizontal lines give the $95 \%$ confidence interval in estimating the mean (Eq. 7). Figure $4 \mathrm{~b}$ shows the individual data points, rather than daily means and confidence intervals. The solid horizontal line shows again the ensemble mean, but the dashed lines now give the $95 \%$ confidence interval of the ensemble distribution $\left[\bar{X}-t_{\alpha / 2, N-1} S, \bar{X}+t_{\alpha / 2, N-1} S\right]$. We would expect $95 \%$ of the data points to lie within this confidence interval, meaning that 18 points can fall outside of it. Perturbed data points are no more likely to fall outside the unperturbed confidence interval than unperturbed data points. If autocorrelations in the data were taken into account, the confidence interval would be larger, and fewer points would fall outside of it.

Our analysis shows that a $15 \%$ change in nucleation rate throughout the atmosphere does not lead to a response in surface $\mathrm{CCN}_{70}$ that is statistically significant within the noise of natural variability. The maximum absolute difference between perturbed and unperturbed surface $\mathrm{CCN}_{70}$ is $0.7 \mathrm{~cm}^{-3}$, which occurs 12 days after the onset of the perturbation, on

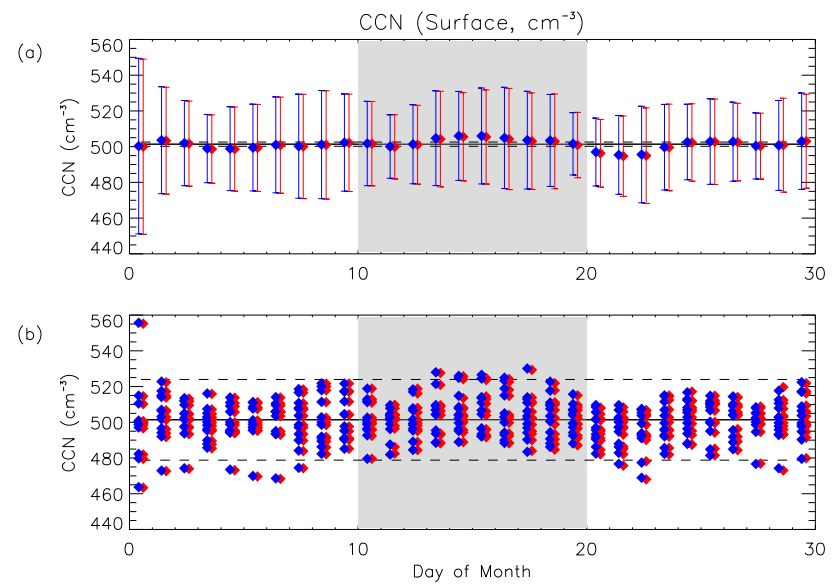

Fig. 4. Surface-level CCN. In both parts of each plot, the solid horizontal line shows the mean of all 360 measurements. Blue diamonds represent unperturbed values, and red diamonds represent perturbed values. (a) The dashed horizontal lines show the uncertainty on the mean, as given in Eq. (7). The diamonds show the daily means, and the error bars show the $95 \%$ confidence interval of the distribution between the months on that day, as given in Eq. (6). The ensemble mean is always within the $95 \%$ CI for both perturbed and unperturbed runs. (b) The dashed horizontal lines show the $95 \%$ confidence internal of the ensemble, and the diamonds show each of the individual measurements on that day. The perturbed data are no more likely to fall outside this limit than the unperturbed data.

day 22 of the epoch (Table 4). The response is equivalent to only a $0.15 \%$ change in $\mathrm{CCN}$ concentration and is comparable in magnitude to the percentage change calculated by Snow-Kropla et al. (2011).

\subsection{Results for other parameters}

\subsubsection{Global mean statistics}

The results of the Lilliefors test and the Brown-Forsythe test for all global mean data are given in Table 1, and the results of the F-test in Table 2. No statistically significant response in aerosol concentrations or optical properties was calculated. 

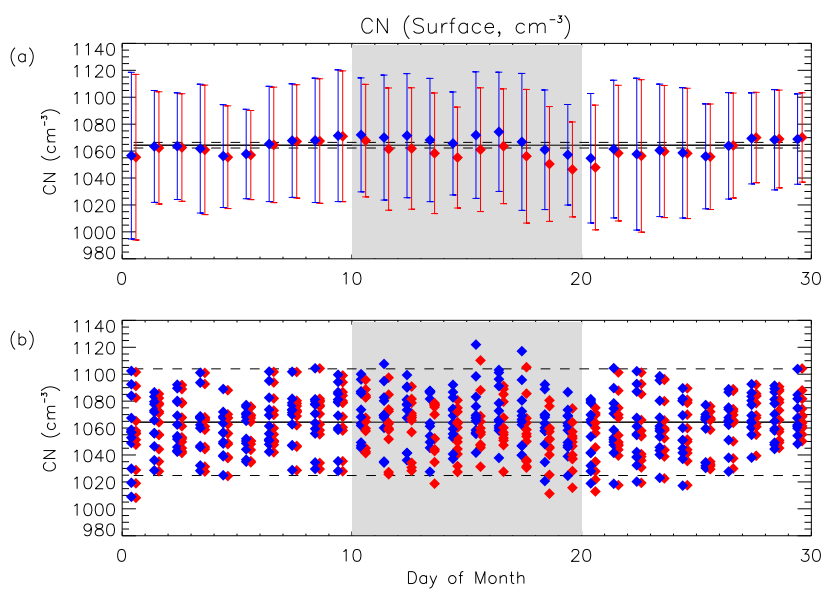

Fig. 5. Time series of surface-level $N_{10}$. In both parts of each plot, the solid horizontal line shows the mean of all 360 measurements. Blue diamonds represent unperturbed values, and red diamonds represent perturbed values. (a) The dashed horizontal lines show the uncertainty on the mean, as given in Eq. (7). The diamonds show the daily means, and the error bars show the $95 \%$ confidence interval of the distribution between the months on that day, as given in Eq. (6). The ensemble mean is always within the $95 \%$ CI for both perturbed and unperturbed runs. (b) The dashed horizontal lines show the $95 \%$ confidence internal of the ensemble, and the diamonds show each of the individual measurements on that day. The perturbed data are no more likely to fall outside this limit than the unperturbed data.

Global mean $N_{10}$ concentrations respond much more quickly and more strongly to changes in the nucleation rate than $\mathrm{CCN}_{70}$, because the response of $\mathrm{CCN}_{70}$ is damped by the coagulation losses of nuclei as they grow to $70 \mathrm{~nm}$. Responses of CCN and $N_{10}$ are compared in Figs. 4 and 5; only $N_{10}$ concentrations decrease noticeably during the period of reduced nucleation, by about $10.9 \mathrm{~cm}^{-3}$ against a mean value of about $1064 \mathrm{~cm}^{-1}$. The response in $N_{10}$ is strongest at the surface because the nucleation rate in the boundary layer $J_{\mathrm{BLN}}=A\left[\mathrm{H}_{2} \mathrm{SO}_{4}\right]$ is higher than in the free troposphere, so the $15 \%$ decrease in the nucleation rate has a larger effect. A nucleation mechanism depending on ionisation rate would tend to have a maximum effect in the free troposphere. However, even with an upper limit assumption of nucleation in the boundary layer the response is not statistically significant.

At $10-15 \mathrm{~km}$ the model predicts that the concentrations of $N_{10}$ increase slightly in response to a decrease in nucleation rate, as shown in Table 4 . This may be caused by the decreased competition for condensable vapour during the period of reduced nucleation, allowing existing particles to grow up to CCN sizes. It should be noted that the null hypothesis of normality was rejected for $\mathrm{CCN}_{70}$ at $10-15 \mathrm{~km}$. Since Forbush et al. (1983) recommend caution in accepting the significance of a signal rather than rejecting it, we suggest that our conclusions about significance are valid despite the lack of normality in $\mathrm{CCN}_{70}$. Figure 6 shows the raw and

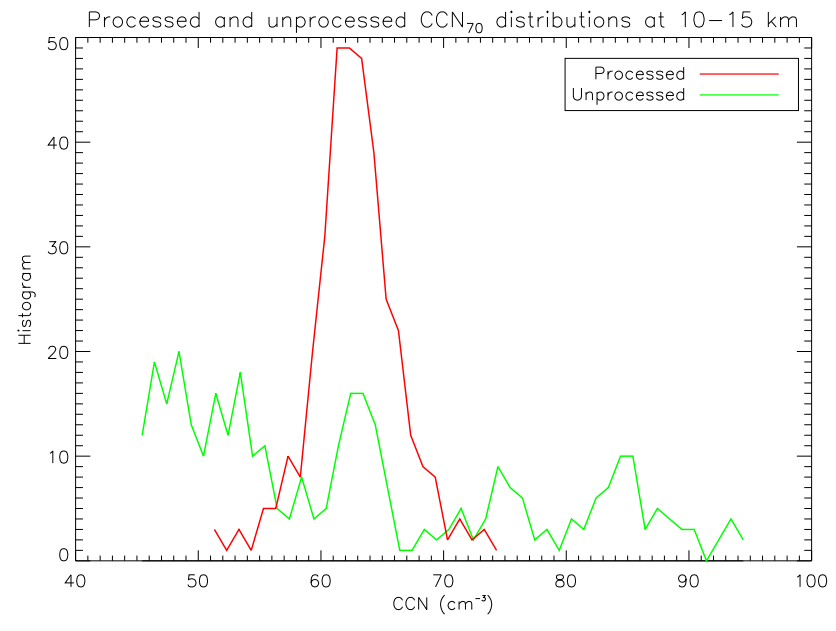

Fig. 6. Histograms showing the distribution of processed and unprocessed $\mathrm{CCN}_{70}$ concentrations at $10-15 \mathrm{~km}$. The null hypothesis that the red line (processed) is normally distributed is rejected by the Lilliefors test.

detrended $\mathrm{CCN}_{70}$ distributions at $10-15 \mathrm{~km}$ altitude. The rejection of the null hypothesis of normality is most likely due to the distribution's fat tails.

The null hypothesis of normality was also rejected for Ångström exponent. Figure 7 suggests that in the case of the Ångström exponent, the population's distribution is thintailed; no data points fall outside of the calculated $95 \%$ confidence interval of the ensemble mean. The thin-tailed $\mathrm{AE}_{340-440}$ distribution implies that the true expected variability is smaller than would be accounted for by an F-test.

\subsubsection{Model grid point statistics}

To take advantage of the full spatial resolution of our global aerosol microphysics model, we have performed the F-test on $N_{10}$ and $\mathrm{CCN}_{70}$ in each of the 253952 grid boxes, and $\mathrm{AE}_{340-440}$ for each integrated column. Table 3 shows the proportion of unperturbed and perturbed grid boxes for which the variation between days is found to be statistically significantly greater than the residual variance in that grid box.

Perturbing the nucleation rate causes a small increase in the number of grid boxes for which the null hypothesis is rejected (that is, for which $F=S_{\mathrm{c}}^{2} / S_{\mathrm{R}}^{2}>F_{\alpha}$ ) for both $N_{10}$ and $\mathrm{CCN}_{70}$, but a small decrease in the case of $\mathrm{AE}_{340-440}$. No distinctive pattern in the response over land or ocean was observed. Figure 8a shows the number of model altitude levels for which $F>F_{\alpha}$ in the case of unperturbed $N_{10}$. Large local variations in $N_{10}$ concentrations will result in higher $\mathrm{F}$-values. Figure $8 \mathrm{~b}$ shows the difference in regional significance between unperturbed and perturbed data sets. The differences are small and do not show any kind of geographical trend. At the surface there is a mean increase in grid boxes 

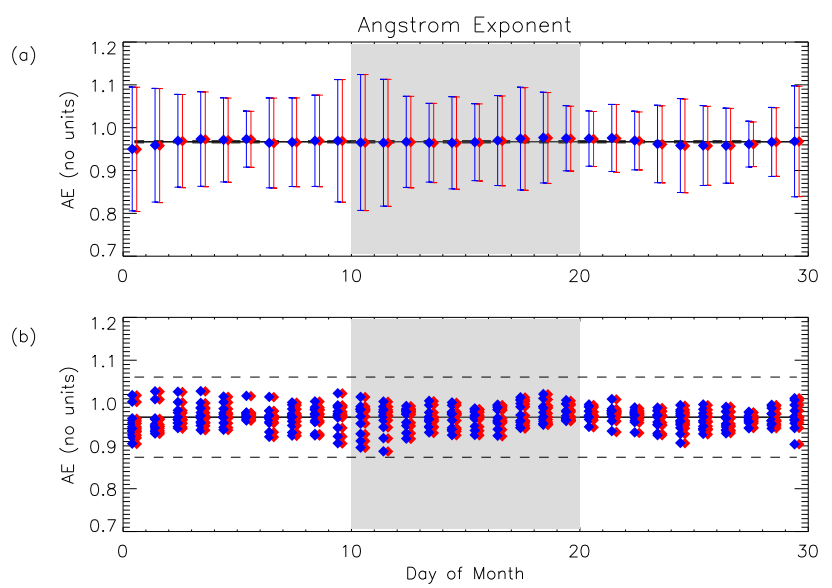

Fig. 7. Ångström exponent. In both parts of each plot, the solid horizontal line shows the mean of all 360 measurements. Blue diamonds represent unperturbed values, and red diamonds represent perturbed values. (a) The dashed horizontal lines show the uncertainty on the mean, as given in Eq. (7). The diamonds show the daily means, and the error bars show the $95 \%$ confidence interval of the distribution between the months on that day, as given in Eq. (6). The ensemble mean is always within the $95 \%$ CI for both perturbed and unperturbed runs. (b) The dashed horizontal lines show the $95 \%$ confidence internal of the ensemble, and the diamonds show each of the individual measurements on that day. The perturbed data are no more likely to fall outside this limit than the unperturbed data.

Table 3. The number and percentage of grid boxes for which the F-test found that variance between different days of the month was statisticially significantly greater than the variance between different months. In the case of $N_{10}$ and $\mathrm{CCN}_{70}$, there is a small increase in the number of gridboxes which have a statisticially significant F-statistic, but for $\mathrm{AE}_{340-440}$ there is a small decrease. There are fewer grid boxes overall for $\mathrm{AE}_{340-440}$ because it is a columnintegrated quantity.

\begin{tabular}{lrrr}
\hline Variable & \# gridboxes & $\begin{array}{r}\text { \% significant } \\
\text { unperturbed }\end{array}$ & $\begin{array}{r}\% \text { significant } \\
\text { perturbed }\end{array}$ \\
\hline$N_{10}$ & 253952 & $11.67 \%$ & $11.87 \%$ \\
$\mathrm{CCN}_{70}$ & 253952 & $11.18 \%$ & $11.23 \%$ \\
$\mathrm{AE}_{340-440}$ & 8192 & $15.22 \%$ & $14.97 \%$ \\
\hline
\end{tabular}

where $F>F_{\alpha}$ of $\sim 1 \%$ for $N_{10}$ but only a $0.15 \%$ increase for $\mathrm{CCN}_{70}$.

Table 4 shows the maximum difference between perturbed and unperturbed data averaged over 12 months. The largest difference at $1-3 \mathrm{~km}$ is $1.18 \%$ for $N_{10}$ and $0.18 \%$ for $\mathrm{CCN}_{70}$. Table 5 shows the maximum difference between perturbed and unperturbed data from each day in the year.
Table 4. The maximum absolute difference between unperturbed and perturbed data averaged over the 12 months, as both an absolute value and a percentage, as well as the day of the month on which the maximum difference occurred.

\begin{tabular}{lrrr}
\hline Variable & $\begin{array}{r}\text { Max. abs. } \\
\text { diff. }\left(\mathrm{cm}^{-3}\right)\end{array}$ & $\begin{array}{r}\text { Max. \% } \\
\text { diff }(\%)\end{array}$ & $\begin{array}{r}\text { Day of } \\
\text { month }\end{array}$ \\
\hline Surface $N_{10}$ & 10.9 & -1.03 & 20 \\
$N_{10}$ at $1-3 \mathrm{~km}$ & 9.1 & -1.18 & 19 \\
$N_{10}$ at $10-15 \mathrm{~km}$ & 5.9 & +0.50 & 13 \\
Surface $\mathrm{CCN}_{70}$ & 0.7 & -0.15 & 22 \\
$\mathrm{CCN}_{70}$ at $1-3 \mathrm{~km}$ & 0.7 & -0.18 & 20 \\
$\mathrm{CCN}_{70}$ at $10-15 \mathrm{~km}$ & 0.2 & -0.35 & 28 \\
$\mathrm{AE}_{340-440}$ & 0.001 & -0.11 & 22 \\
\hline
\end{tabular}

\section{Conclusions}

The two main questions concerning possible correlations between cosmic ray fluctuations and aerosol and cloud properties (Svensmark et al., 2009) are whether the observed correlations are causally linked and, if so, what mechanism could link them on the time scale of days. Laken et al. (2009), C̆alogović et al. (2010) and Laken and C̆alogović (2011) all concluded that there were no significant correlations between cloud and aerosol properties and Forbush decreases. Laken et al. (2010) suggested that under the right conditions, a change in the GCR flux might affect cloud cover, but that it was unlikely to be via the mechanism of ion-induced nucleation. To date, none of the papers looking at the response of cloud and aerosol properties to Forbush decreases has used superposed epoch analysis, and this is likely to affect the validity of their findings.

Here we have tested the significance of changes in $N_{10}$ and $\mathrm{CCN}$ in response to transient reductions in the nucleation rate in a global aerosol model. Although we have limited our study to perturbations of the neutral nucleation rate, the applied decrease in the nucleation rate is comparable to or slightly larger than the decrease that would occur after the strongest Forbush decreases assuming all nucleation is ion-induced. The estimated fraction of nucleated particles derived from ion-mediated processes varies between $6 \%$ to $15 \%$ based on observations in the continental boundary layer (Boy et al., 2008; Gagné et al., 2008; Manninen et al., 2009) to about $80 \%$ in the model of Yu and Turco (2008). During a Forbush decrease, ions in the continental boundary layer are expected to change by at most $5 \%$, though at high altitudes over the poles they could change by up to $20 \%$.

Under well-controlled model conditions and with a known control aerosol state, our model produces a response in global mean surface $N_{10}$ of $1.03 \%$ and in $\mathrm{CCN}_{70}$ of $0.15 \%$ based on the superposition of 12 Forbush-type events through the year. Our value for $\mathrm{CCN}_{70}$ compares well with Snow-Kropla et al. (2011)'s figure of $0.13 \%$ for $\mathrm{CCN}_{80}$. Our value for $N_{10}$ is larger than their figure of $0.16 \%$, which is to be expected 


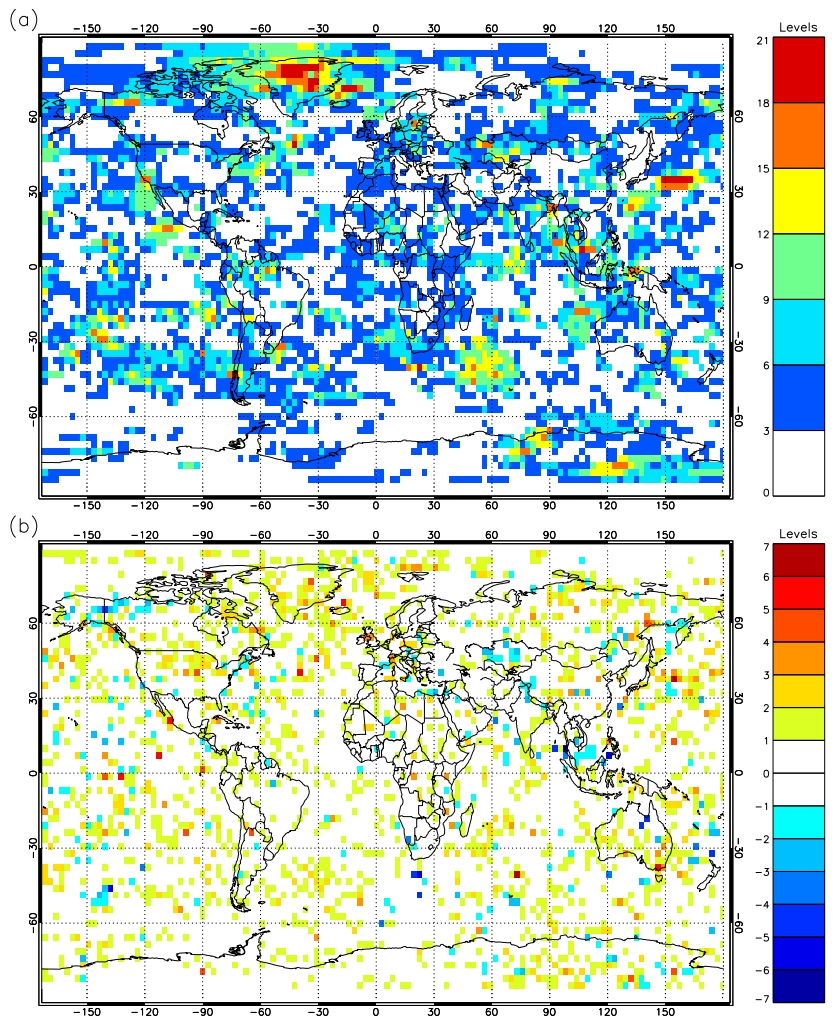

Fig. 8. A map showing regional values of (a) the number of model levels (from a total of 31) where $F>F_{\alpha}$, and (b) the difference between unperturbed and perturbed data in number of model levels where $F>F_{\alpha}$ for the case of $N_{10}$.

Table 5. The maximum absolute difference between unperturbed and perturbed data, as both an absolute value and a percentage, as well as the day and the month on which the maximum difference occurred.

\begin{tabular}{lrrrl}
\hline Variable & $\begin{array}{r}\text { Max. abs. } \\
\text { diff. }\left(\mathrm{cm}^{-3}\right)\end{array}$ & $\begin{array}{r}\text { Max.\% } \\
\text { diff }(\%)\end{array}$ & $\begin{array}{r}\text { Day of } \\
\text { month }\end{array}$ & Month \\
\hline Surface $N_{10}$ & 14.8 & 1.39 & 20 & Mar \\
$N_{10}$ at $1-3 \mathrm{~km}$ & 12.6 & 1.57 & 17 & Jan \\
$N_{10}$ at $10-15 \mathrm{~km}$ & 14.8 & 1.27 & 22 & Jul \\
Surface $\mathrm{CCN}_{70}$ & 1.8 & 0.37 & 18 & Mar \\
$\mathrm{CCN}_{70}$ at $1-3 \mathrm{~km}$ & 1.5 & 0.42 & 19 & Jun \\
$\mathrm{CCN}_{70}$ at $10-15 \mathrm{~km}$ & 0.8 & 1.23 & 28 & Jun \\
$\mathrm{AE}_{340-440}$ & 0.003 & 0.28 & 15 & Mar \\
\hline
\end{tabular}

for two reasons: the change in ion concentrations near the surface is smaller than in the free troposphere, leading to a response in their ion-mediated nucleation parametrisation much smaller than $15 \%$; and our boundary layer nucleation mechanism will generate much larger nucleation rates, leading to a larger absolute change in the nucleation rate. However, several statistical tests in our study show that these changes in $N_{10}$ and $\mathrm{CCN}_{70}$ would not be sufficiently greater than natural variability to be detectable in a blind study in which the control aerosol state is not known.

Our study agrees with that of Snow-Kropla et al. (2011) that the model-predicted changes in $N_{10}$ and CCN would not be sufficiently large to generate Svensmark et al. (2009)'s observed changes in cloud properties. Thus, based on two fairly sophisticated global models and independent assumptions about the nucleation processes, transient decreases in nucleation rate accompanying Forbush events would not result in a global mean response in aerosol or cloud properties that is detectable above natural variability.

We have also questioned the very existence of a correlation between aerosol and cloud properties and Forbush events (Dunne, 2012). The statistical analyses we have applied here go beyond those used in Svensmark et al. (2012) to detect significant changes in aerosol properties. While Svensmark et al. (2012) looked for aerosol changes that were outside the $95 \%$ confidence interval, they did not remove the trend from each epoch being analysed, nor did they test for normality of the underlying data. We have argued (Dunne, 2012) that the approach of Svensmark et al. (2012), which is much less rigorous than for example that of Forbush et al. (1983), could lead to false positives. Thus, we suggest that our model results are consistent with the observations analysed in Svensmark et al. (2012), which we argue do not reveal a statistically significant response of global aerosol to Forbush events.

The principal limitation of our study is that we have used a large-scale global model that can only resolve processes operating on the scale of greater than about $100 \mathrm{~km}$. While the model nucleation processes on this scale result in spatial and temporal patterns in $N_{10}$ that agree fairly well with observations (Spracklen et al., 2006, 2008, 2010; Reddington et al., 2011), we cannot preclude the existence of ion-aerosol processes operating on smaller scales. For example, nucleation in the near-cloud environment under highly perturbed conditions of aerosol, trace vapours and ion density may behave differently to the kind of events that the global model has been set up to capture: namely, nucleation events that are known to occur on large spatial scales (Hussein et al., 2008, 2009). We have also not addressed the possibility of cloud responses to changes in electrification, as studied by Tinsley et al. (2000); Tripathi and Harrison (2002); Harrison and Ambaum (2008, among others).

Acknowledgements. The authors would like to thank Jeff Pierce for very helpful discussion. This research has received funding from the EC's Seventh Framework Programme under grant agreement no. 215072 (Marie Curie Initial Training Network "CLOUDITN"). $F_{\alpha}$ was calculated using the single-calculation tool from http://www.stattools.net/FTest_Pgm.php.

Edited by: N. M. Donahue 


\section{References}

Arnold, F.: Atmospheric Aerosol and Cloud Condensation Nuclei Formation, Space Sci. Rev., 125, 169-186, 2007.

Beard III, K. V., H. T. O., and Twohy, C. H.: Aircraft measurements of high average charges on cloud drops in layer clouds, Geophys. Res. Lett., 31, L1411, doi:10.1029/2004GL020465, 2004.

Berresheim, H., Elste, T., Tremmel, H. G., Allen, A. G., Hansson, H., Rosman, K., Maso, M. D., Mäkelä, J. M., Kulmala, M., and O'Dowd, C. D.: Gas-aerosol relationships of H2SO4, MSA, and $\mathrm{OH}$ : observations in the coastal marine boundary layer at Mace Head, Ireland, J. Geophys. Res., 107, 8100, doi:10.1029/2000JD000229, 2002.

Bond, G., Kromer, B., Beer, J., Muscheler, R., Evans, M. N., Showers, W., Hoffmann, S., Lotti-Bond, R., Hajdas, I., and Bonani, G.: Persistent solar influence on north atlantic climate during the holocene, Science, 294, 2130-2136, 2001.

Bondo, T., Enghoff, M. B., and Svensmark, H.: Model of optical response of marine aerosols to Forbush decreases, Atmos. Chem. Phys., 10, 2765-2776, doi:10.5194/acp-10-2765-2010, 2010.

Boy, M., Kazil, J., Lovejoy, E., Guenther, A., and Kulmala, M.: Relevance of ion-induced nucleation of sulfuric acid and water in the lower troposphere over the boreal forest at northern latitudes, Atmos. Res., 90, 151-158, 2008.

Brown, M. B. and Forsythe, A. B.: Robust tests for the equality of variances", J. Am. Stat. Assoc., 69, 364-367, 1974.

C̆alogović, J., Albert, C., Arnold, F., Beer, J., Desorgher, L., and Flueckiger, E. O.: Sudden cosmic ray decreases: No change of global cloud cover, Geophys. Res. Lett., 37, L03802, doi:10.1029/2009GL041327, 2010.

Carslaw, K. S., Harrison, R. G., and Kirkby, J.: Cosmic rays, clouds, and climate, Science, 298, 1732-1737, 2002.

Chipperfield, M. P.: New version of the TOMCAT/SLIMCAT offline chemical transport model: Intercomparison of stratospheric tracer experiments, Q. J. Roy. Meteor. Soc., 132, 1179-1203, 2006.

Dentener, F., Kinne, S., Bond, T., Boucher, O., Cofala, J., Generoso, S., Ginoux, P., Gong, S., Hoelzemann, J. J., Ito, A., Marelli, L., Penner, J. E., Putaud, J.-P., Textor, C., Schulz, M., van der Werf, G. R., and Wilson, J.: Emissions of primary aerosol and precursor gases in the years 2000 and 1750 prescribed data-sets for AeroCom, Atmos. Chem. Phys., 6, 4321-4344, doi:10.5194/acp-64321-2006, 2006.

Dunne, E. M.: Interactive comment on "Effects of cosmic ray decreases on cloud microphysics" by J. Svensmark et al., Atmos. Chem. Phys. Discuss., 12, C1000, 2012.

Durilleul, P. and Legendre, P.: Lack of robustness in two tests of normality against autocorrelation in sample data, J. Stat. Comput. Sim., 42, 79-91, 1992.

Eichler, A., Olivier, S., Henderson, K., Laube, A., Beer, J., Papina, T., Gäggeler, H. W., and Schwikowski, M.: Temperature response in the altai region lags solar forcing, Geophys. Res. Lett., 36, L01808, doi:10.1029/2008GL035930, 2009.

Enghoff, M. B., Pedersen, J. O. P., Uggerhøj, U. I., Paling, S. M., and Svensmark, H.: Aerosol nucleation induced by a high energy particle beam, Geophys. Res. Lett., 38, 4 pp., doi:10.1029/2011GL047036, 2011.

Forbush, S. E.: On the effects in cosmic-ray intensity observed during the recent magnetic storm, Phys. Rev, 51, 1108-1109, 1937.
Forbush, S., Duggal, S., Pomerantz, M., and Tsao, C.: Random Fluctuations, Persistence, and Quasi-Persistence in Geophysical and Cosmical Periodicities: A Sequel, Rev. Geophys. Space Ge., 20, 971-976, 1982.

Forbush, S., Pomerantz, M., Duggal, S., and Tsao, C.: Statistical considerations in the analysis of solar oscillation data by the superposed epoch method, Sol. Phys., 82, 113-122, 1983.

Gagné, S., Laakso, L., Petäjä, T., Kerminen, V., and Kulmala, M.: Analysis of one year of Ion-DMPS data from the SMEAR II station, finland, Tellus B, 60, 318-329, 2008.

Gong, S. L.: A parameterization of sea-salt aerosol source function for sub- and super-micron particles, Global Biogeochem. Cy., 17, 1097, doi:10.1029/2003GB002079, 2003.

Haigh, J.: The impact of solar variability on climate, Science, 272, 981-984, 1996.

Haigh, J. D., Winning, A. R., Toumi, R., and Harder, J. W.: An influence of solar spectral variations on radiative forcing of climate, Nature, 467, 696-699, 2010.

Hald, A.: Statistical Theory with Engineering Applications, John Wiley \& Sons, 1952.

Harrison, R. G.: Discrimination between cosmic ray and solar irradiance effects on clouds, and evidence for geophysical modulation of cloud thickness, P. Roy. Soc. A: Math. Phy., 464, 25752590, 2008.

Harrison, R. G. and Ambaum, M. H. P.: Enhancement of cloud formation by droplet charging, P. Roy. Soc. A: Math. Phy., 464, 2561-2573, 2008.

Harrison, R. G., Ambaum, M. H. P., and Lockwood, M.: Cloud base height and cosmic rays, Proceedings of the Royal Society A: Mathematical, Physical and Engineering Science, 467, 27772791, 2011.

Hussein, T., Martikainen, J., Junninen, H., Sogacheva, L., Wagner, R., Dal Maso, M., Riipinen, I., Aalto, P. P., and Kulmala, M.: Observation of regional new particle formation in the urban atmosphere, Tellus B, 60, 509-521, 2008.

Hussein, T., Junninen, H., Tunved, P., Kristensson, A., Dal Maso, M., Riipinen, I., Aalto, P. P., Hansson, H.-C., Swietlicki, E., and Kulmala, M.: Time span and spatial scale of regional new particle formation events over Finland and Southern Sweden, Atmos. Chem. Phys., 9, 4699-4716, doi:10.5194/acp-9-4699-2009, 2009.

Kazil, J., Zhang, K., Stier, P., Feichter, J., Lohmann, U., and O'Brien, K.: The present-day decadal solar cycle modulation of earth's radiative forcing via charged $\mathrm{H}_{2} \mathrm{SO}_{4} / \mathrm{H}_{2} \mathrm{O}$ aerosol nucleation, Geophys. Res. Lett., 39, L02805, doi:10.1029/2011GL050058, 2012.

Kerminen, V. and Kulmala, M.: Analytical formulae connecting the, J. Aerosol Sci., 33, 609-622, 2002.

Kirkby, J.: Cosmic rays and climate, Surv. Geophys., 28, 333-375, 2007.

Kirkby, J., Curtius, J., Almeida, J., Dunne, E., Duplissy, J., Ehrhart, S., Franchin, A., Gagne, S., Ickes, L., Kuerten, A., Kupc, A., Metzger, A., Riccobono, F., Rondo, L., Schobesberger, S., Tsagkogeorgas, G., Wimmer, D., Amorim, A., Bianchi, F., Breitenlechner, M., David, A., Dommen, J., Downard, A., Ehn, M., Flagan, R. C., Haider, S., Hansel, A., Hauser, D., Jud, W., Junninen, H., Kreissl, F., Kvashin, A., Laaksonen, A., Lehtipalo, K., Lima, J., Lovejoy, E. R., Makhmutov, V., Mathot, S., Mikkila, J., Minginette, P., Mogo, S., Nieminen, T., Onnela, A., Pereira, P., 
Petaja, T., Schnitzhofer, R., Seinfeld, J. H., Sipila, M., Stozhkov, Y., Stratmann, F., Tome, A., Vanhanen, J., Viisanen, Y., Vrtala, A., Wagner, P. E., Walther, H., Weingartner, E., Wex, H., Winkler, P. M., Carslaw, K. S., Worsnop, D. R., Baltensperger, U., and Kulmala, M.: Role of sulphuric acid, ammonia and galactic cosmic rays in atmospheric aerosol nucleation, Nature, 476, 429-U77, 2011.

Kulmala, M., Laaksonen, A., and Pirjola, L.: Parameterizations for sulfuric acid/water nucleation rates, J. Geophys. Res., 103, 8301, doi:10.1029/97JD03718, 1998.

Kulmala, M., Laakso, L., Lehtinen, K. E. J., Riipinen, I., Dal Maso, M., Anttila, T., Kerminen, V.-M., Hõrrak, U., Vana, M., and Tammet, H.: Initial steps of aerosol growth, Atmos. Chem. Phys., 4, 2553-2560, doi:10.5194/acp-4-2553-2004, 2004.

Kulmala, M., Lehtinen, K. E. J., and Laaksonen, A.: Cluster activation theory as an explanation of the linear dependence between formation rate of $3 \mathrm{~nm}$ particles and sulphuric acid concentration, Atmos. Chem. Phys., 6, 787-793, doi:10.5194/acp-6-787-2006, 2006.

Laakso, L., Gagné, S., Petäjä, T., Hirsikko, A., Aalto, P. P., Kulmala, M., and Kerminen, V.-M.: Detecting charging state of ultrafine particles: instrumental development and ambient measurements, Atmos. Chem. Phys., 7, 1333-1345, doi:10.5194/acp-71333-2007, 2007.

Laken, B. A. and C̆alogović, J.: Solar irradiance, cosmic rays and cloudiness over daily timescales, Geophys. Res. Lett., 38, L24811, doi:10.1029/2011GL049764, 2011.

Laken, B. A. and Čalogović, J.: Interactive comment on "Effects of cosmic ray decreases on cloud microphysics" by J. Svensmark et al., Atmos. Chem. Phys. Discuss., 12, C962-973, 2012.

Laken, B., Wolfendale, A., and Kniveton, D.: Cosmic ray decreases and changes in the liquid water cloud fraction over the oceans, Geophys. Res. Lett., 36, L23803, doi:10.1029/2009GL040961, 2009.

Laken, B. A., Kniveton, D. R., and Frogley, M. R.: Cosmic rays linked to rapid mid-latitude cloud changes, Atmos. Chem. Phys., 10, 10941-10948, doi:10.5194/acp-10-10941-2010, 2010.

Lilliefors, H. W.: On the Kolmogorov-Smirnov test for normality with mean and variance unknown, J. Am. Stat. Assoc., 62, 399402, 1967.

Manninen, H. E., Nieminen, T., Riipinen, I., Yli-Juuti, T., Gagné, S., Asmi, E., Aalto, P. P., Petäjä, T., Kerminen, V.-M., and Kulmala, M.: Charged and total particle formation and growth rates during EUCAARI 2007 campaign in Hyytiälä, Atmos. Chem. Phys., 9, 4077-4089, doi:10.5194/acp-9-4077-2009, 2009.

Marsh, N. D. and Svensmark, H.: Low cloud properties influenced by cosmic rays, Phys. Rev. Lett., 85, 5004-5007, 2000.

Massey, F. J.: The Kolmogorov-Smirnov test for goodness of fit, J. Am. Stat. Assoc., 46, 68-78, 1951.

Meehl, G. A., Arblaster, J. M., Branstator, G., and van Loon, H.: A coupled Air-Sea response mechanism to solar forcing in the pacific region, J. Climate, 21, 2883-2897, 2008.

Merikanto, J., Spracklen, D. V., Mann, G. W., Pickering, S. J., and Carslaw, K. S.: Impact of nucleation on global CCN, Atmos. Chem. Phys., 9, 8601-8616, doi:10.5194/acp-9-8601-2009, 2009.

Neff, U., Burns, S. J., Mangini, A., Mudelsee, M., Fleitmann, D., and Matter, A.: Strong coherence between solar variability and the monsoon in oman between 9 and 6[thinsp]kyr ago, Nature,
411, 290-293, 2001.

Nightingale, P. D., Malin, G., Law, C. S., Watson, A. J., Liss, P. S., Liddicoat, M. I., Boutin, J., and Upstill-Goddard, R. C.: In situ evaluation of air-sea gas exchange parameterizations using novel conservative and volatile tracers, Global Biogeochem. Cy., 14, 373-387, 2000.

Pierce, J. R. and Adams, P. J.: Efficiency of cloud condensation nuclei formation from ultrafine particles, Atmos. Chem. Phys., 7, 1367-1379, doi:10.5194/acp-7-1367-2007, 2007.

Pierce, J. R. and Adams, P. J.: Can cosmic rays affect cloud condensation nuclei by altering new particle formation rates?, Geophys. Res. Lett., 36, L09820, doi:10.1029/2009GL037946, 2009a.

Pierce, J. R. and Adams, P. J.: Uncertainty in global CCN concentrations from uncertain aerosol nucleation and primary emission rates, Atmos. Chem. Phys., 9, 1339-1356, doi:10.5194/acp-91339-2009, 2009b.

Pudovkin, M. I. and Veretenenko, S. V.: Cloudiness decreases associated with forbush-decreases of galactic cosmic rays, J. Atmos. Terr. Phys., 57, 1349 - 1355, 1995.

Reddington, C. L., Carslaw, K. S., Spracklen, D. V., Frontoso, M. G., Collins, L., Merikanto, J., Minikin, A., Hamburger, T., Coe, H., Kulmala, M., Aalto, P., Flentje, H., Plass-Dülmer, C., Birmili, W., Wiedensohler, A., Wehner, B., Tuch, T., Sonntag, A., O'Dowd, C. D., Jennings, S. G., Dupuy, R., Baltensperger, U., Weingartner, E., Hansson, H.-C., Tunved, P., Laj, P., Sellegri, K., Boulon, J., Putaud, J.-P., Gruening, C., Swietlicki, E., Roldin, P., Henzing, J. S., Moerman, M., Mihalopoulos, N., Kouvarakis, G., Ždímal, V., Zíková, N., Marinoni, A., Bonasoni, P., and Duchi, R.: Primary versus secondary contributions to particle number concentrations in the European boundary layer, Atmos. Chem. Phys., 11, 12007-12036, doi:10.5194/acp-11-12007-2011, 2011.

Rossow, B.: International satellite cloud climatology project (ISCCP), Technical report, Institute for Space Studies, NASA Goddard Space Flight Centre, 1996.

Russell, L. M., Pandis, S. N., and Seinfeld, J. H.: Aerosol production and growth in the marine boundary layer, J. Geophys. Res., 99, 20989-21003, 1994.

Rypdal, K.: Interactive comment on "Effects of cosmic ray decreases on cloud microphysics" by J. Svensmark et al., Atmos. Chem. Phys. Discuss., 12, C247-C255, 2012.

Schuster, G. L., Dubovik, O., and Holben, B. N.: Angström exponent and bimodal aerosol size distributions, J. Geophys. Res., 111, D07207, doi:10.1029/2005JD006328, 2006.

Shapiro, S. S. and Wilk, M. B.: An analysis of variance test for normality (Complete samples), Biometrika, 52, 591-611, 1965.

Sihto, S.-L., Kulmala, M., Kerminen, V.-M., Dal Maso, M., Petäjä, T., Riipinen, I., Korhonen, H., Arnold, F., Janson, R., Boy, M., Laaksonen, A., and Lehtinen, K. E. J.: Atmospheric sulphuric acid and aerosol formation: implications from atmospheric measurements for nucleation and early growth mechanisms, Atmos. Chem. Phys., 6, 4079-4091, doi:10.5194/acp-6-4079-2006, 2006.

Smith, M. and Harrison, N.: The sea spray generation function, J. Aerosol Sci., 29, 189-190, 1998.

Snow-Kropla, E. J., Pierce, J. R., Westervelt, D. M., and Trivitayanurak, W.: Cosmic rays, aerosol formation and cloudcondensation nuclei: sensitivities to model uncertainties, Atmos. Chem. Phys., 11, 4001-4013, doi:10.5194/acp-11-4001-2011, 2011. 
Spracklen, D. V., Pringle, K. J., Carslaw, K. S., Chipperfield, M. P., and Mann, G. W.: A global off-line model of size-resolved aerosol microphysics: II. Identification of key uncertainties, Atmos. Chem. Phys., 5, 3233-3250, doi:10.5194/acp-5-3233-2005, 2005.

Spracklen, D. V., Carslaw, K. S., Kulmala, M., Kerminen, V.-M., Mann, G. W., and Sihto, S.-L.: The contribution of boundary layer nucleation events to total particle concentrations on regional and global scales, Atmos. Chem. Phys., 6, 5631-5648, doi:10.5194/acp-6-5631-2006, 2006.

Spracklen, D. V., Pringle, K. J., Carslaw, K. S., Mann, G. W., Manktelow, P., and Heintzenberg, J.: Evaluation of a global aerosol microphysics model against size-resolved particle statistics in the marine atmosphere, Atmos. Chem. Phys., 7, 2073-2090, doi:10.5194/acp-7-2073-2007, 2007.

Spracklen, D. V., Carslaw, K. S., Kulmala, M., Kerminen, V., Sihto, S., Riipinen, I., Merikanto, J., Mann, G. W., Chipperfield, M. P., Wiedensohler, A., Birmili, W., and Lihavainen, $\mathrm{H}$.: Contribution of particle formation to global cloud condensation nuclei concentrations, Geophys. Res. Lett., 35, L06808, doi:10.1029/2007GL033038, 2008.

Spracklen, D. V., Carslaw, K. S., Merikanto, J., Mann, G. W., Reddington, C. L., Pickering, S., Ogren, J. A., Andrews, E., Baltensperger, U., Weingartner, E., Boy, M., Kulmala, M., Laakso, L., Lihavainen, H., Kivekäs, N., Komppula, M., Mihalopoulos, N., Kouvarakis, G., Jennings, S. G., O’Dowd, C., Birmili, W., Wiedensohler, A., Weller, R., Gras, J., Laj, P., Sellegri, K., Bonn, B., Krejci, R., Laaksonen, A., Hamed, A., Minikin, A., Harrison, R. M., Talbot, R., and Sun, J.: Explaining global surface aerosol number concentrations in terms of primary emissions and particle formation, Atmos. Chem. Phys., 10, 4775-4793, doi:10.5194/acp-10-4775-2010, 2010

Svensmark, H. and Friis-Christensen, E.: Variation of cosmic ray flux and global cloud coverage - a missing link in solar-climate relationships, J. Atmos. Sol-Terr. Phys., 59, 1225-1232, 1997.

Svensmark, H., Bondo, T., and Svensmark, J.: Cosmic ray decreases affect atmospheric aerosols and clouds, Geophys. Res. Lett., 36, L15101, doi:10.1029/2009GL038429, 2009.

Svensmark, J., Enghoff, M. B., and Svensmark, H.: Effects of cosmic ray decreases on cloud microphysics, Atmos. Chem. Phys. Discuss., 12, 3595-3617, doi:10.5194/acpd-12-35952012, 2012.

Tinsley, B., Rohrbaugh, R., Hei, M., and Beard, K.: Effects of image charges on the scavenging of aerosol particles by cloud droplets and on droplet charging and possible ice nucleation processes, $\mathrm{J}$. Atmos. Sci., 57, 2118-2134, 2000.

Tripathi, S. N. and Harrison, R.: Enhancement of contact nucleation by scavenging of charged aerosol particles, Atmos. Res., 62, 5770, 2002.

Twomey, S.: The electrification of individual cloud droplets, Tellus, 8, 445-452, 1956.
Usoskin, I. G. and Kovaltsov, G. A.: Cosmic ray induced ionization in the atmosphere: Full modeling and practical applications, J. Geophys. Res., 111, D21206, doi:10.1029/2006JD007150, 2006.

Usoskin, I. G., Alanko-Huotari, K., Kovaltsov, G. A., and Mursula, K.: Heliospheric modulation of cosmic rays: Monthly reconstruction for 1951-2004, J. Geophys. Res., 110, A12108, doi:10.1029/2005JA011250, 2005.

Vehkamäki, H., Kulmala, M., Napari, I., Lehtinen, K. E. J., Timmreck, C., Noppel, M., and Laaksonen, A.: An improved parameterization for sulfuric acid-water nucleation rates for tropospheric and stratospheric conditions, J. Geophys. Res., 107, 4622, doi:10.1029/2002JD002184, 2002.

Wang, P. K., Grover, S. N., and Pruppacher, H. R.: On the effect of electric charges on the scavenging of aerosol particles by clouds and small raindrops, J. Atmos. Sci., 35, 1735-1743, 1978.

Wilks, D. S.: Resampling hypothesis tests for autocorrelated fields, J. Climate, 10, 65-82, 1997.

Willson, R. C.: Total solar irradiance trend during solar cycles 21 and 22, Science, 277, 1963-1965, 1997.

Yu, F.: Ion-mediated nucleation in the atmosphere: Key controlling parameters, implications, and look-up table, J. Geophys. Res., 115, D03206, doi:10.1029/2009JD012630, 2010.

Yu, F. and Turco, R.: Case studies of particle formation events observed in boreal forests: implications for nucleation mechanisms, Atmos. Chem. Phys., 8, 6085-6102, doi:10.5194/acp-86085-2008, 2008.

Yu, F. and Luo, G.: Simulation of particle size distribution with a global aerosol model: contribution of nucleation to aerosol and CCN number concentrations, Atmos. Chem. Phys., 9, 76917710, doi:10.5194/acp-9-7691-2009, 2009.

Yu, F. and Turco, R. P.: The size-dependent charge fraction of sub-3nm particles as a key diagnostic of competitive nucleation mechanisms under atmospheric conditions, Atmos. Chem. Phys., 11, 9451-9463, doi:10.5194/acp-11-9451-2011, 2011.

Yu, F., Luo, G., Bates, T. S., Anderson, B., Clarke, A., Kapustin, V., Yantosca, R. M., Wang, Y., and Wu, S.: Spatial distributions of particle number concentrations in the global troposphere: Simulations, observations, and implications for nucleation mechanisms, J. Geophys. Res., 115, D17205, doi:10.1029/2009JD013473, 2010.

Zhang, K., Feichter, J., Kazil, J., Wan, H., Zhuo, W., Griffiths, A. D., Sartorius, H., Zahorowski, W., Ramonet, M., Schmidt, M., Yver, C., Neubert, R. E. M., and Brunke, E.-G.: Radon activity in the lower troposphere and its impact on ionization rate: a global estimate using different radon emissions, Atmos. Chem. Phys., 11, 7817-7838, doi:10.5194/acp-11-7817-2011, 2011.

Zhang, Y., McMurry, P. H., Yu, F., and Jacobson, M. Z.: A comparative study of nucleation parameterizations: 1. examination and evaluation of the formulations, J. Geophys. Res., 115, D20212, doi:10.1029/2010JD014150, 2010. 